\title{
LOCAL TIME ASYMMETRIES OF THE SSC-ASSOCIATED HYDROMAGNETIC VARIATIONS AT THE GEOSYNCHRONOUS ALTITUDE
}

\author{
Masayuki KuwaShima $^{1}$ and Hiroshi FukUnishi ${ }^{2}$ \\ ${ }^{1}$ Kakioka Magnetic Observatory, 595, Kakioka, Yasato-machi, Niihari-gun, Ibaraki 315-01 \\ ${ }^{2}$ National Institute of Polar Research, 9-10, Kaga 1-chome, Itabashi-ku, Tokyo 173
}

\begin{abstract}
SSC events have been studied by using the data observed at the multiple satellites at the geosynchronous altitude. The strong local time asymmetry of the SSC amplitude which was found by KokUBUn (J. Geophys. Res., $\mathbf{8 8}, 10025,1983$ ) has been confirmed. The pronounced local time asymmetry has also been found with the direction of the initial movement of Psc magnetic pulsations. Those local time effects are interpreted by the intensification of the magnetopause surface current during an SSC event, and by the distance between the geosynchronous satallite and the surface current. It has also been clarified that the SSC signal propagates with a speed of $400-700 \mathrm{~km} / \mathrm{s}$ across the field lines in the magnetosphere as suggested by WiLKEN et al. (J. Geophys. Res., 87, 5901, 1982).
\end{abstract}

\section{Introduction}

Various kinds of phenomena are observed in association with a storm sudden commencement (SSC). At middle and low latitudes on the ground, the increase of the horizontal (north-south) component in a range of several tens $n T$ is observed without any local time dependency (KUwASHIMA et al., 1984). At high latitudes on the ground, a preliminary reverse impulse occurs prior to the main impulse (ARAKI, 1977; ArAKI and Allen, 1982). Damped type oscillations are frequently observed associated with SSC (Psc) as reported by Saito and Matsushita (1967) and Kuwashima (1972). However, most of the SSC studies in the past are based on the ground observations. It is necessary to study the characteristics of SSC based on the observation in the magnetosphere.

It will be convenient to use the data obtained at the geosynchronous satellites in a study of the temporal variations such as SSC-associated phenomena. The SSCassociated magnetic variations at the geosynchronous altitude were first examined by Patel and Coleman (1970), who reported that the SSC event observed in the dark sector between 0600 and 1800 LT showed smaller amplitudes compared with that observed in the sunlit sector. Such local time asymmetry of the SSC amplitude at the geosynchronous altitude has been confirmed by KoKuBun (1983), who reported that amplitude ratios (satellite amplitude/ground amplitude) are larger than unity in most cases observed in the sunlit sector between 0600 and 1800 LT, while the SSC amplitude tends to become very small near midnight as compared with that on the ground. KoKUBUN (1983) analyzed 88 SSC events observed during the period from 
1978 to 1979 . In the present study, we will confirm the results of KoKUBUN (1983) using 167 SSC events observed during the period from 1976 to 1980.

The interesting result of the recent studies is the characteristics of the propagation of the SSC signal in the magnetosphere. WILKEN et al. (1982) have studied the spatial and temporal characteristics of the SSC event on July 29, 1977 based on the data obtained at the multiple satellites at the geosynchronous altitude. WILKEN et al. (1982) have clarified that the SSC signal propagates with a speed of $910 \mathrm{~km} / \mathrm{s}$ along the field lines and with a speed of $600 \mathrm{~km} / \mathrm{s}$ across the field lines in the magnetosphere. In the present paper, the characteristics of the SSC signal propagation will be studied statistically.

Satellite data used in the present study are microfilm plots of the magnetic field with $3.06 \mathrm{~s}$ from SMS/GOES series (FrITZ and NeELEY, 1982). In the coordinate system, $H_{\mathrm{p}}$ is parallel to the Earth's rotational axis, $H_{\mathrm{e}}$ is parallel to the radially earthward direction, and $H_{\mathrm{n}}$ is in the east-west direction (positive westward). The dipole coordinate system $(H, V, D)$ will also be used. In the dipole coordinate system, $H$ is parallel to the dipole axis and positive northward, $V$ is radially outward (parallel to the magnetic-equatorial plane), and $D$ is in the east-west direction (positive eastward). For the identification of SSC, normal-run magnetograms $(20 \mathrm{~mm} / \mathrm{h})$ obtained at middle and low latitudes are used. Used stations are $D s t$-index stations which are Kakioka $\left(26.0^{\circ}\right.$ in magnetic latitude and $206.0^{\circ}$ in magnetic longitude), Hermanus $\left(-33.7^{\circ}, 81.7^{\circ}\right)$, San Juan $\left(29.9^{\circ}, 3.2^{\circ}\right)$ and Honolulu $\left(21.1^{\circ}, 266.5^{\circ}\right) .167$ SSC events have been identified from the records at these $D s t$-stations during the period from 1976 to 1980. Rapid-run magnetograms $(6 \mathrm{~mm} / \mathrm{min})$ at Kakioka and Hermanus are also used for identification of the onset time of SSC.

\section{Local Time Asymmetry of the Amplitude of SSC}

Typical SSC-associated magnetic variations observed at the geosynchronous altitude are shown in Fig. 1. As shown in the figure, increases of the $H_{\mathrm{p}}$-component are shown both at GOES 2 and at GOES 3 (shaded pattern in Fig. 1). The increases of the $H_{\mathrm{p}}$-component suggest the effect of the compression of the magnetosphere in association with SSC. In the SSC event on August 18, 1980 (left-hand side of Fig. 1), the onset time of SSC was identified at about 1926 UT. Local time of the SSC onset was 1226 for GOES 2, while it was 1026 for GOES 3, respectively. Though the difference of the local time between the two geosynchronous satellites was only two hours, there was a conspicuous difference in the amplitudes of SSC between the two satellites. The amplitude of SSC (range of increase in the $H_{\mathrm{p}}$-component) was $51.0 \mathrm{nT}$ at GOES 2 (1226 LT), while it was $32.6 \mathrm{nT}$ at GOES 3 (1026 LT). It seems that the amplitude of SSC at the geosynchronous satellite increases with nearing its location to the noon. Such a tendency could also be seen in the SSC event on July 3, 1978 (right-hand side of Fig. 1). The onset time of SSC was at about 2305 UT in this event. Local time was 1805 for GOES 2, while it was 1525 for GOES 3. GOES 3 was located nearer to the noon than GOES 2 during the event, and the amplitude of SSC at GOES 3 was larger than that at GOES 2. The amplitude of SSC was $28.9 \mathrm{nT}$ at GOES 3 (1525 LT) and it was $18.0 \mathrm{nT}$ at GOES 2 (1805 LT). 


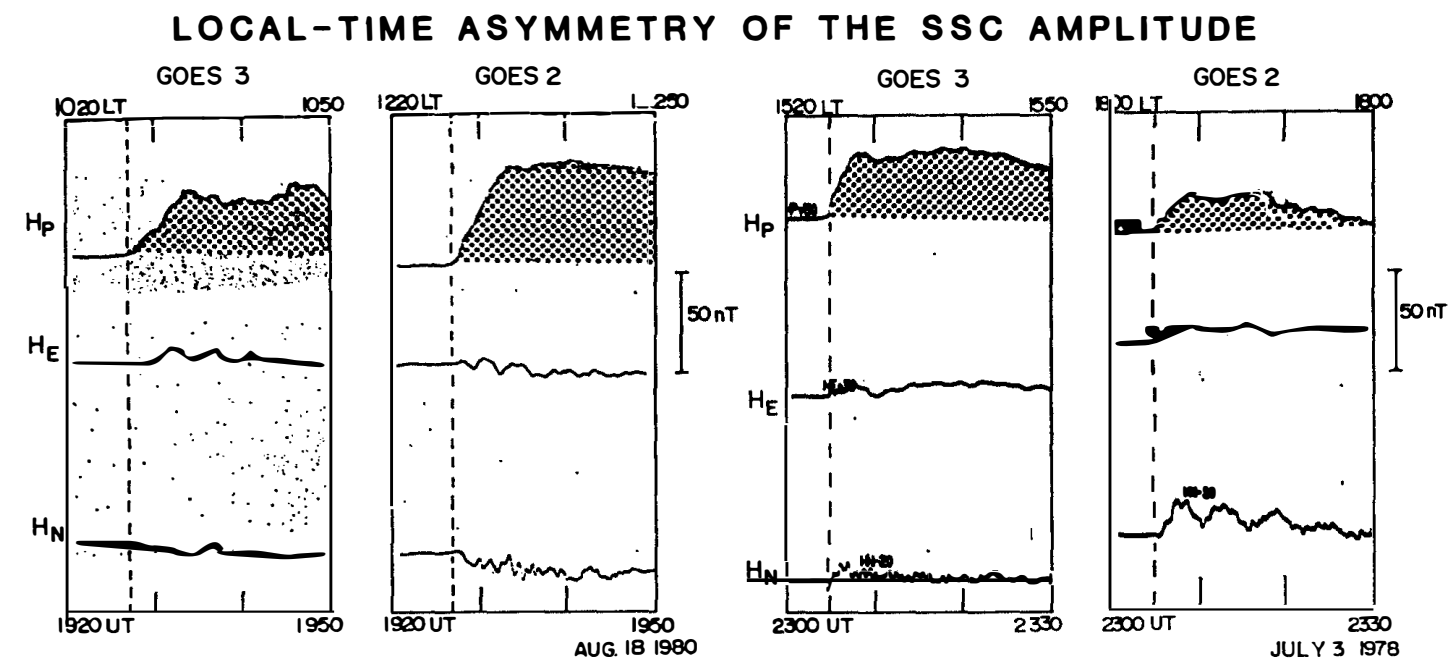

Fig. 1. SSC-associated magnetic variations simultaneously observed at the two geosynchronous satellites, GOES 2 and GOES 3. The onset times of SSC indicated by dotted lines were 1926 UT on August 18, 1980 (left-hand side) and 2305 UT on July 3, 1978 (right-hand side). In the coordinate, $H_{\mathrm{p}}$ is parallel to the Earth's rotational axis, $H_{\mathrm{e}}$ is parallel to the radially earthward direction and $H_{\mathrm{n}}$ is in the east-west direction (positive westward).

Local time asymmetry of the SSC amplitude could be seen more clearly in the statistical results summarized in Fig. 2. In the figure, the amplitude of SSC observed at the geosynchronous altitude was normalized by the following procedure,

$$
B_{\mathrm{n}}=b / B_{\mathrm{g}} \mathrm{nT},
$$

where $b$ is the amplitude of SSC at the geosynchronous altitude, $B_{\mathrm{g}}$ is the averaged

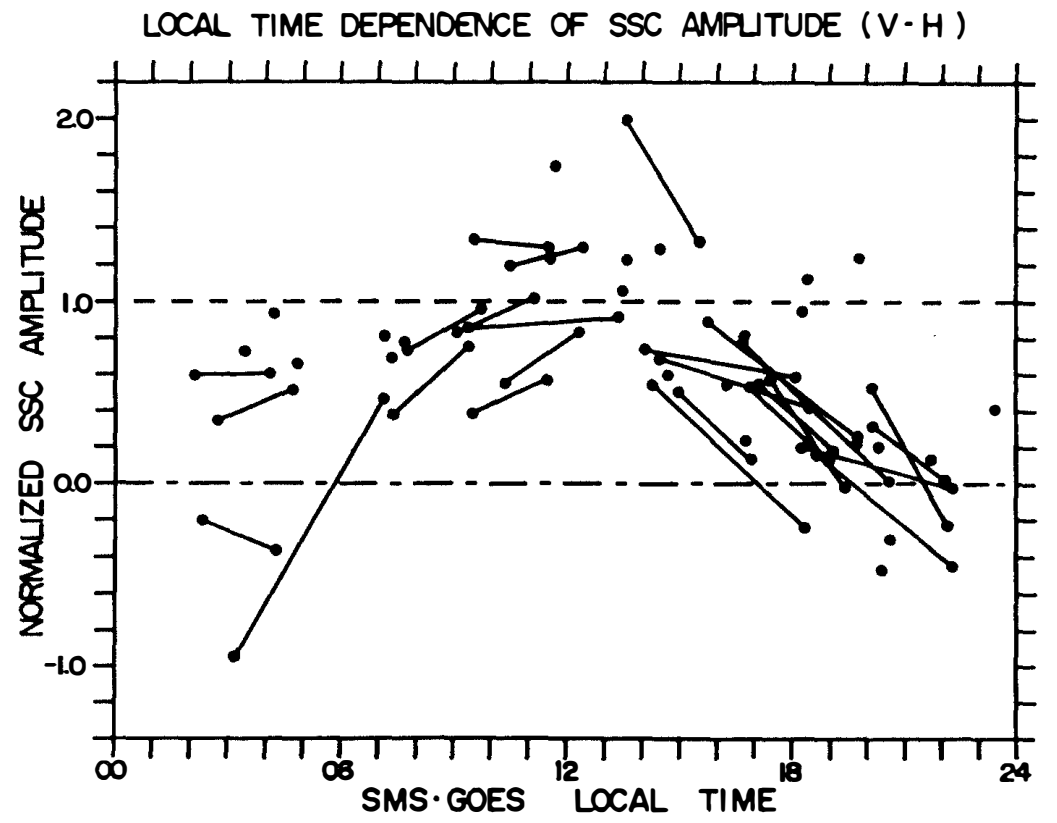

Fig. 2. The normalized amplitude of SSC observed at the geosynchronous altitude. The amplitude of SSC is large in the daytime, whereas it is very small in the night time. 
amplitude of SSC at the Dst-stations on the ground (Kakioka, Hermanus, San Juan and Honolulu). $B_{\mathrm{n}}$ is the normalized amplitude of SSC which is plotted in Fig. 2 as a function of occurrence local time. The results shown in Fig. 2 confirm the pronounced local time asymmetry of the amplitude of SSC at the geosynchronous altitude. The amplitude of SSC is very large in the daytime, whereas it is very small near the midnight. The results shown in Fig. 2 suggest that the SSC event could not be interpreted simply by the compression of the whole magnetosphere.

\section{Local Time Asymmetry of the Initial Movement of Psc}

It is well known that the hydromagnetic oscillation is excited in association with SSC (Saito and Matsushita, 1967; Kuwashima, 1972). That hydromagnetic oscillations are called the magnetic Psc pulsations (Psc). Psc is also observed at the geosynchronous altitude as reported by KUWASHIMA et al. (1984) and SAKURAI et al. (1984). Psc at the geosynchronous altitude shows the most dominant oscillation in the eastwest component. Figure 3 shows two typical examples of Psc observed at the geosynchronous altitude. In the SSC event on April 30, 1978 (left-hand side of Fig. 3), Psc started at about 0952 UT coincidently with the onset of SSC (dotted line). The Psc oscillation was most dominantly in the east-west component $\left(H_{\mathrm{n}}\right)$ as shown in the figure. It should be noted that the direction of the initial movement of Psc was eastward (negative $H_{\mathrm{n}}$ ) in the SSC event on April 30. During that event, GOES 2 satellite was located in the morning-side (0452 LT).

On the other hand, the direction of the initial movement of Psc was westward

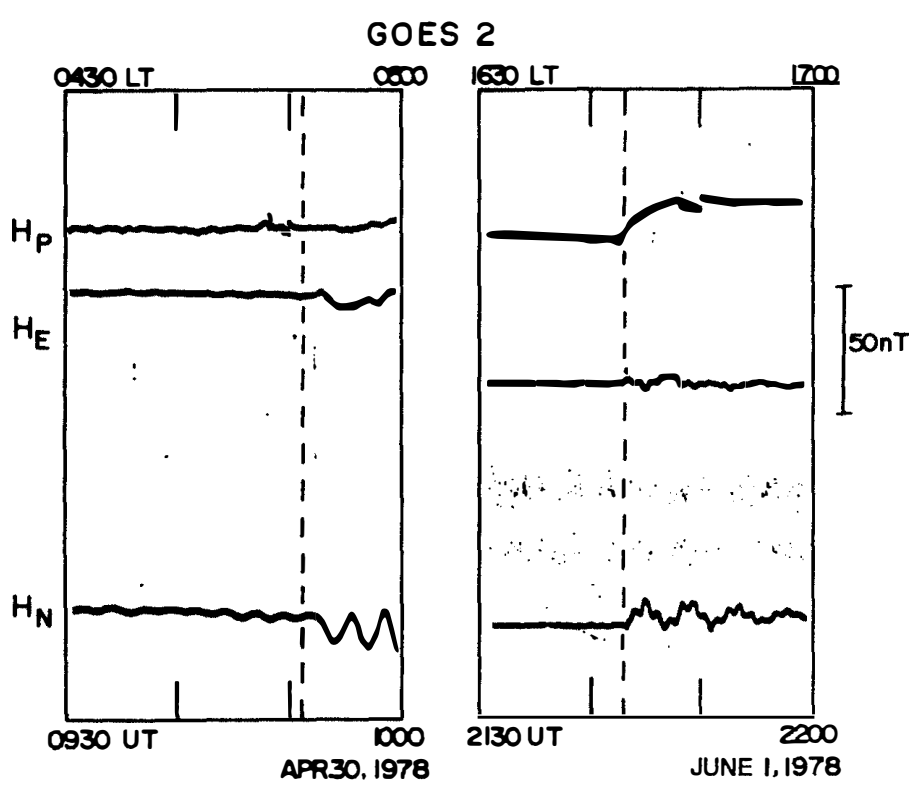

Fig. 3. Psc oscillations observed at the geosynchronous altitude. Psc oscillations are most dominantly in the east-west component $\left(H_{\mathrm{n}}\right.$-component). The direction of the initial movement of Psc is eastward (negative $H_{n}$ ) in the morning as shown in the left-hand of the figure, while it is westward (positive $H_{\mathrm{n}}$ ) in the afternoon as shown in the right-hand of the figure. 
(positive $H_{\mathrm{n}}$ ) in the SSC event on June 1, 1978 (right-hand side of Fig. 3). During that event, GOES 2 was located in the afternoon-side (1640 LT). The results shown in Fig. 3 suggest that the initial movement of Psc is eastward in the morning, while it is westward in the afternoon at the geosynchronous altitude. This tendency will be confirmed statistically by the results summarized in Fig. 4. It is clarified in the figure that the direction of the initial movement of Psc changed across the noon from the eastward movement in the morning to the westward one in the afternoon.

The results in Fig. 4 will give a question that how Psc-associated hydromagnetic perturbations (which are perpendicular to the ambient magnetic field direction) are related with the phenomena in the auroral region on the ground. The perpendicular perturbation will propagate along the field lines with Alfvén velocity and reach the Earth's surface through the ionosphere. The field lines which intersect the geosynchronous altitude in the magnetosphere $\left(6.5 R_{\mathrm{E}}\right)$ would be anchored in the auroral region on the ground $(L=6-7)$. Figure 5 shows typical Psc events observed in the auroral region, Syowa Station in Antarctica $(L=6.1)$. Psc oscillations are illustrated

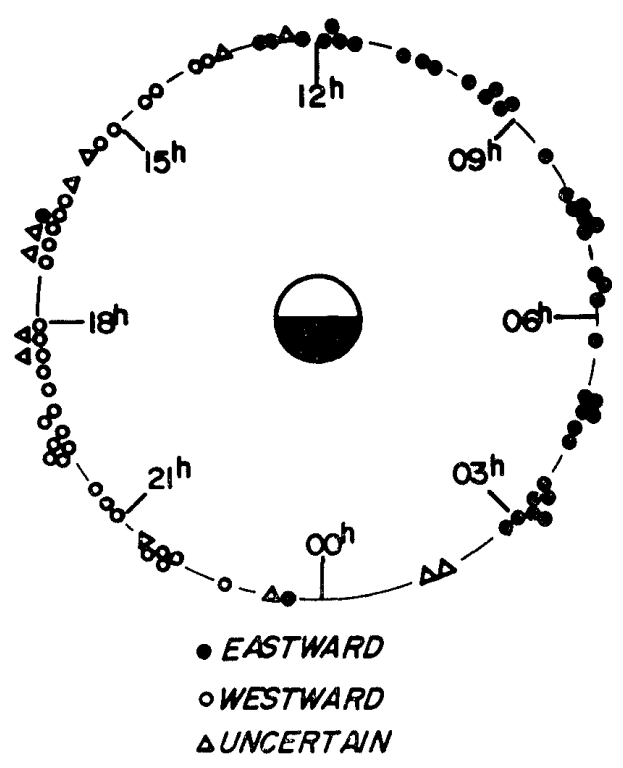

Fig. 4. Distribution of the direction of the initial movement of Psc at the geosynchronous altitude in the magnetosphere.

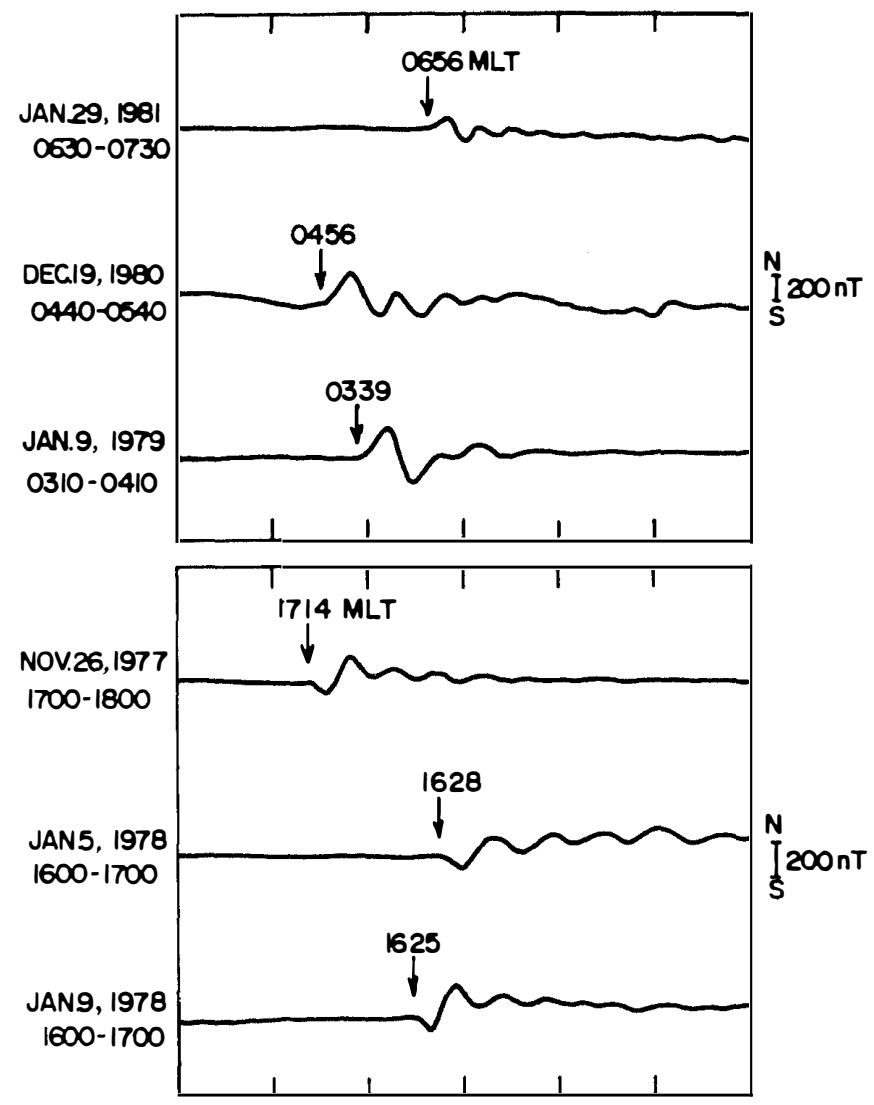

Fig. 5. Psc oscillations observed on the ground, Syowa Station $(L=6.1)$. Psc oscillations are most dominantly in the north-south component in the auroral region. The direction of the initial movement of Psc is northward in the morning (upper panel), whereas it is southward in the afternoon (bottom panel). 


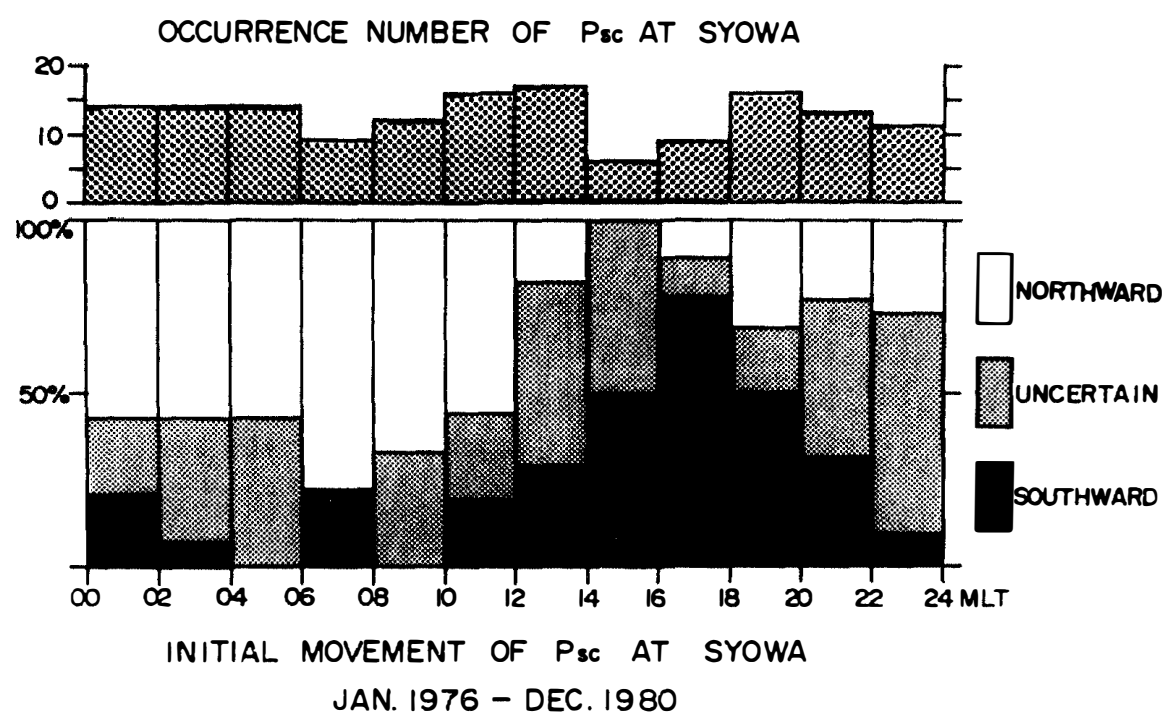

Fig. 6. Distribution of the direction of the initial movement of Psc in the auroral region, Syowa Station $(L=6.1)$.

Table 1. Initial movement of Psc.

\begin{tabular}{lll}
\hline & Morningside & Eveningside \\
\hline Space $\sim 6.5 R_{\mathrm{E}}$ above equatorial-plane & Eastward & Westward \\
Ground $L \sim 6.1$ & Northward & Southward \\
\hline
\end{tabular}

only for the north-south component in Fig. 5, because Psc is more dominantly in the north-south component than in the east-west component in the auroral region (KuWASHIma et al., 1984). Figure 5 suggests that the direction of the initial movement of Psc is northward in the morning (upper part of Fig. 5), while it is southward in the afternoon (bottom part of Fig. 5). That tendency will be confirmed statistically by the results summarized in Fig. 6, where the distributions of the initial movement of Psc at Syowa Station $(L=6.1)$ are presented using the coordinates of the occurrence probability and occurrence local time. As shown in the figure, the northward movement is dominant in the morning, while the southward movement is dominant in the afternoon. The local time asymmetries of the direction of the initial movement of Psc are confirmed both at the geosynchronous altitude in the magnetosphere and in the auroral region on the ground. Those observational results are summarized in Table 1.

Before detected on the ground, the SSC signal must propagate through the ionosphere. The ionospheric screening effects cause the rotation of the major axis of the wave polarization about $90^{\circ}$. As summarized in Table 1, Psc oscillation is dominantly in the east-west component at the geosynchronous altitude $\left(6.5 R_{\mathrm{E}}\right)$ in the magnetosphere, while it is dominantly in the north-south component in the auroral region on the ground $(L=6-7)$. Those results are consistent with the theoretical prediction proposed by theoretical research workers for years (NiSHIDA, 1964; TAMAO, 1964; HugheS and Southwood, 1976). 


\section{Propagation of the SSC Signal in the Magnetosphere}

WILKEN et al. (1982) have extensively studied the characteristics of the propagation of the SSC signal in the magnetosphere based on the data obtained at the multiple satellites. According to their results, the velocity of the SSC signal was estimated at about $600 \mathrm{~km} / \mathrm{s}$ in a propagation across the field lines in the magnetosphere. The characteristics of the propagation of the SSC signal will be also studied statistically in the present section.

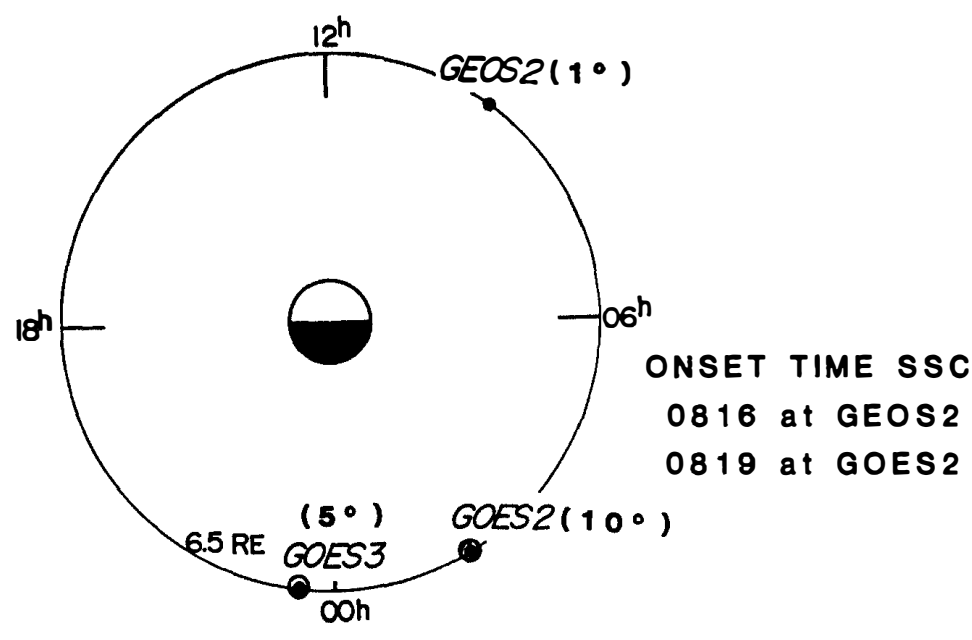

MAR. 6, 1979

Fig. 7. Locations of the geosynchronous satellites, GEOS 2, GOES 2 and GOES 3 during the SSC event on March 6, 1979.

The method of the analyses is outlined in Figs. 7 and 8. Figure 7 shows the locations of the geosynchronous satellites (GEOS 2, GOES 2 and GOES 3) during the SSC event on March 6, 1979. This SSC event has been studied in detail by BAUMJOHANN et al. (1984). The magnetic latitudes of these satellites are $1^{\circ}$ for GEOS $2,10^{\circ}$ for GOES 2 , and $5^{\circ}$ for GOES 3. It should be noted that GOES 2 was located off the magnetic equatorial plane. Psc magnetic oscillations would be observed effectively there, because Psc is caused by the fundamental mode of the hydromagnetic standing oscillation (KoKUBUN, 1983). On the other hand, GEOS 2 was located almost on the magnetic equatorial plane. Psc magnetic oscillations would be hardly observed there. Figure 8 shows SSC-associated variations observed at the geosynchronous satellites shown in Fig. 7. The variations illustrated in the figure are the plasma drift velocity $\left(U_{\mathrm{s}}\right.$ and $\left.U_{\mathrm{n}}\right)$, the magnetic variation $(V, D$ and $H)$ observed at GEOS 2, the magnetic variation $\left(H_{\mathrm{e}}, H_{\mathrm{n}}\right.$ and $\left.H_{\mathrm{p}}\right)$ observed at GOES 2, and the magnetic variation $\left(H_{\mathrm{e}}, H_{\mathrm{n}}\right.$ and $\left.H_{\mathrm{p}}\right)$ observed at GOES 3. At GEOS 2, an onset time of SSC was identified at about 0816 UT by the start of the oscillation of the plasma drift velocity and the start of the increase of the magnetic $H$-component. Local time of GEOS 2 during the SSC event was about $11 \mathrm{~h} \mathrm{LT}$. An onset of SSC at GOES 2 was identified at about 0819 UT by the start of the Psc oscillation in the $H_{\mathrm{n}}$-component. Local time of GOES 2 during the SSC event was about $02 \mathrm{~h} \mathrm{LT}$. The time difference of the 

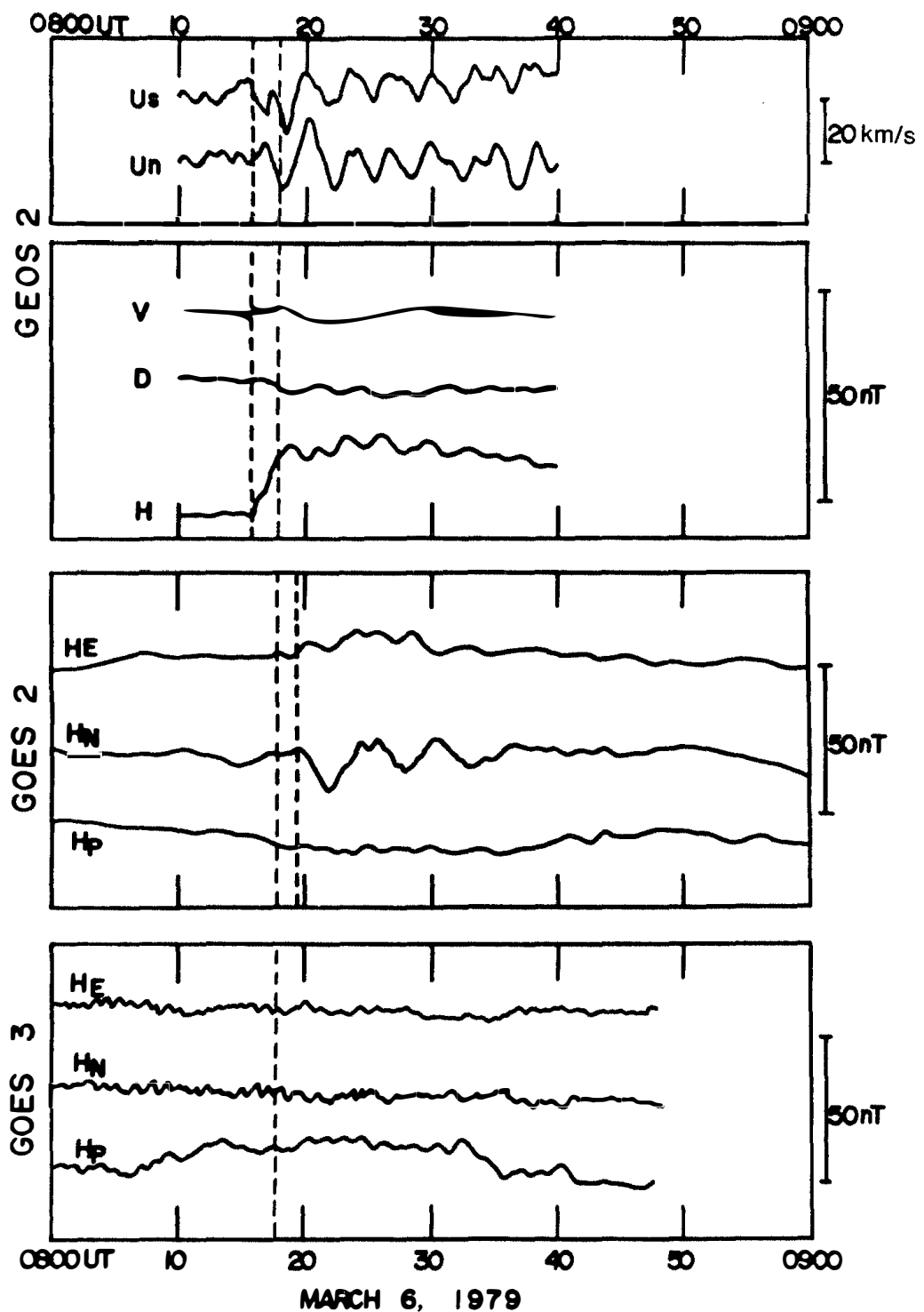

Fig. 8. SSC-associated variations simultaneously observed at the three geosynchronous satellites, GEOS 2, GOES 2 and GOES 3. $U_{\mathrm{8}}$ and $U_{\mathrm{n}}$ show the plasma drift velocities in the sun-earth and east-west directions. Magnetic variations are illustrated by the dipole coordinate system $(V, D, H)$ at GEOS 2 , while by $H_{\mathrm{e}}, H_{\mathrm{n}}$ and $H_{\mathrm{p}}$ system at GOES 2 and GOES 3. The onset time of SSC was at about 0816 UT (1030 LT) at GEOS 2, while it was 0819 UT $(0130 \mathrm{LT})$ at GOES 2. The onset time identified from the ground-based stations was 0818 UT.

onset of SSC is about 3 min between GEOS $2(11 \mathrm{~h} \mathrm{LT})$ and GOES $2(02 \mathrm{~h} \mathrm{LT})$. This time difference indicates that the SSC signal propagates across the field lines in the magnetosphere with a velocity about $450 \mathrm{~km} / \mathrm{s}$. In Fig. 8, we could not find any conspicuous SSC-associated variation at GOES 3 because of the following two reasons. The one is that GOES 3 was located in the midnight $(23 \mathrm{~h} \mathrm{LT})$ so that the amplitude of SSC was expected to be very small (Fig. 3). The other is that GOES 3 was located near the magnetic-equatorial plane so that the amplitude of Psc was expected to be very small (KoKUBUN, 1983). 


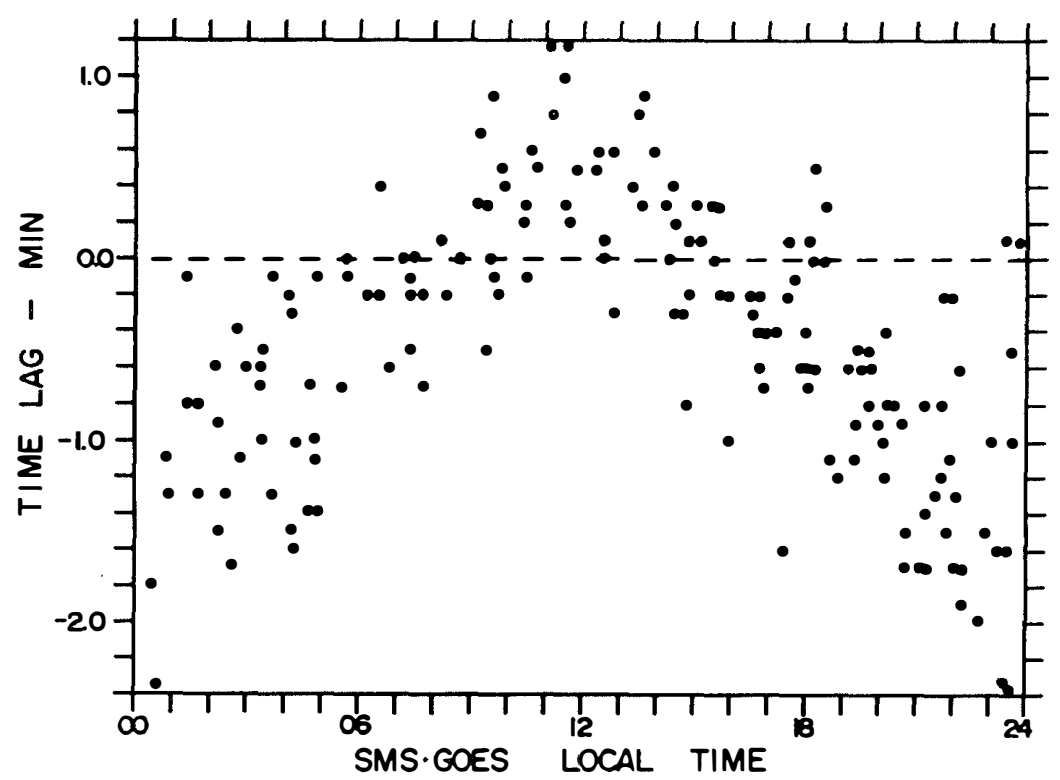

Fig. 9. Difference of the onset time of SSC between the geosynchronous satellites and the groundbased stations. The start of SSC at the geosynchronous altitude is faster than that on the daytime, whereas it is later in the nighttime.

The onset time of SSC at the geosynchronous altitude has been studied using the onset time identified in the ground observation as a reference signal. In Fig. 8, the onset time was identified at about 0818 UT on the ground. The statistical results are summarized in Fig. 9. As shown in the figure, the onset of SSC at the geosynchronous altitude is earlier by $0.5 \pm 0.5 \mathrm{~min}$ than that on the ground in the daytime, while it is later by $1.0 \pm 0.5 \mathrm{~min}$ than that on the ground in the night time. These results indicate that the SSC signal propagates with the velocity of $400-700 \mathrm{~km} / \mathrm{s}$ across the field lines in the magnetosphere. The results shown in Fig. 9 are consistent with that by WILKEN et al. (1982).

\section{Discussion}

We have confirmed the very pronounced local time asymmetry of the amplitude of SSC at the geosynchronous altitude which was found by KoKUBUn (1983). We have also found the local time asymmetry with the direction of the initial movement of Psc magnetic pulsations. As suggested by KoKUBUn (1983), those local time asymmetries are considered to be related with the configuration of the magnetic field intensity in the magnetosphere. The configuration is closely related with the surface current on the magnetopause, the ring current in the magnetosphere, and the current in the magneto-tail. It is supposed that the magnetopause surface current is intensified during an SSC event. We have calculated the magnetic field intensity at the geosynchronous altitude using the magnetic model proposed by OLSON and PfITZER (1974). The calculated results are illustrated in Fig. 10. The local time asymmetries observed at the geosynchronous altitude will be interpreted by the results in Fig. 10. The figure shows that the total force ( $H$-component) is always increased in the day- 


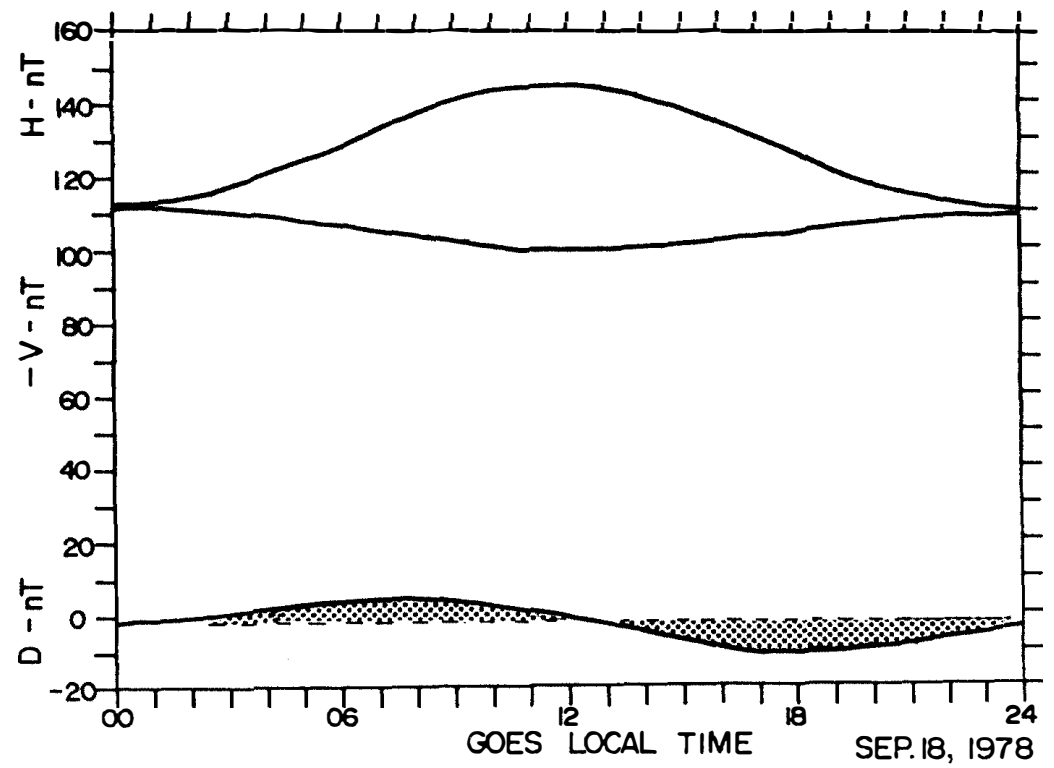

Fig. 10. Typical diurnal variation of the magnetic field intensity at the geosynchronous altitude, for the $H$ (parallel to the ambient magnetic field direction) component, and for the $D$ (parallel to the eastward direction) component.

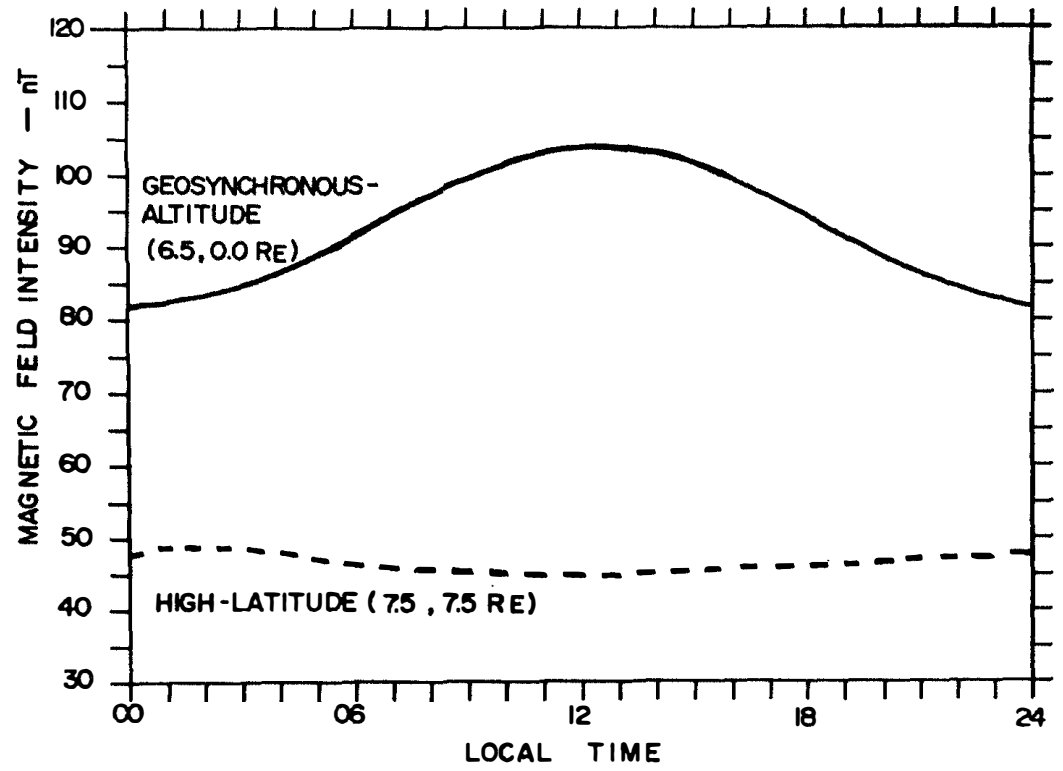

Fig. 11. Typical diurnal variations of the magnetic field intensity of the total force at the geosynchronous altitude (full line) and at the high-latitude (dotted line) in the magnetosphere.

time, while it is always decreased in the nighttime at the geosynchronous altitude in the magnetosphere. Those local time effects are interpreted by considering a distance between the magnetopause surface current and the geosynchronous satellite. The local time asymmetry of the amplitude of SSC will become larger during the SSC event, because the magnetopause surface current is intensified in association with SSC. Those explanations are almost similar to that of KoKUBUN (1983). 
The characteristics of the SSC amplitude in the magnetosphere were studied also by ONDOH (1970). However, the local time asymmetry of the SSC amplitude as shown in Figs. 1 and 2 could not be seen in the results by ONDOH (1970). The observation by ONDOH (1970) was made at high-latitudes in the magnetosphere using the OGO 5 satellite. In order to examine the characteristics at high-latitudes as well as at the geosynchronous altitude, we calculated magnetic field intensities at both the highlatitude $\left(X=7.5 R_{\mathrm{E}}\right.$ and $Z=7.5 R_{\mathrm{E}}$ ) and the geosynchronous altitude ( $X=6.5 R_{\mathrm{E}}$ and $Z=0 R_{\mathrm{E}}$ ) as shown in Fig. 11. The figure indicates that the local time asymmetry is very small at the high-latitude in the magnetosphere (dotted line), whereas it is very pronounced at the geosynchronous altitude (full line). The local time asymmetry of the SSC amplitude shown in Figs. 1 and 2 is the characteristic which is only observed near the geosynchronous altitude in the magnetosphere.

The local time asymmetry of the initial movement of the Psc oscillations has been found in the present study. The Psc oscillation starts from the eastward movement in the morning, while it starts from the westward movement in the afternoon. Moreover, the direction of the DC level shift in the east-west component is also eastward in the morning and westward in the afternoon as shown in Fig. 3. Those evidences indicate that both the depression in the perpendicular plane to the ambient magnetic field direction (east-west component) and the following Psc oscillation are excited near the geosynchronous altitude in the magnetosphere. The SSC-associated sudden depression in the east-west component will propagate along the field lines with Alfvén velocity, and arrive at the polar ionosphere. The Alfvén signal will be reflected because of the high conductivity there during the disturbed period. The reflected signal will propagate again along the field lines causing the hydromagnetic standing oscillation. The $90^{\circ}$ rotation of the major axis of the Psc polarization ellipse (Table 1) is a conclusive evidence of the existense of the propagation of the Alfvén wave along the field lines which intersect near the geosynchronous altitude of the magnetic-equatorial plane in the magnetosphere and are anchored at the polar ionosphere on the ground.

Behaviors of the initial movement of Psc oscillations at the geosynchronous altitude shown in Figs. 3 and 4 can also be interpreted by using the calculated results in Fig. 10. As shown in the figure, the magnetic field in the east-west component ( $D$-component) is always depressed to the eastward direction in the morning and depressed to the westward direction in the afternoon. That asymmetry is closely related with the relative location of the geosynchronous satellite to the magnetopause surface current. That effect will become large in association with the intensification of the magnetopause surface current during an SSC event. As the results, the local time asymmetry of the initial movement of the Psc oscillation shown Figs. 3 and 4 will be observed at the geosynchronous altitude.

A recent important result of SSC study is the determination of the propagation velocity of the SSC signal in the magnetosphere. According to the study by WILKEN et al. (1982), the SSC signal propagates with a velocity of about $600 \mathrm{~km} / \mathrm{s}$ across the field lines in the magnetosphere. The statistical results derived in the present study (shown in Fig. 9) have confirmed the results by WILKEN et al. (1982). Figure 9 indicates that the SSC signal propagates with the velocity of $400-700 \mathrm{~km} / \mathrm{s}$ across the field lines in the magnetosphere. FrANCIS et al. (1959) calculated the velocities of propagation 
of the SSC signal across the field lines. According to the calculation by FRANCIS et al. (1959), the mean velocity of about $900 \mathrm{~km} / \mathrm{s}$ would be expected near the magneticequatorial plane in the magnetosphere. Taking into account both the uncertainties about the actual plasma density in the outer magnetosphere and the presence of oxygen ions, the lower Alfvén velocity in the range of $400-700 \mathrm{~km} / \mathrm{s}$ will be acceptable.

\section{Conclusion}

The pronounced local time asymmetries are confirmed with the magnetic variations associated with SSC at the geosynchronous altitude.

(1) The amplitude of SSC is very large in the daytime, whereas it is very small in the nighttime.

(2) The direction of the initial movement of Psc is eastward in the morning, while it is westward in the afternoon.

Those local time asymmetries are caused by the local time dependency of the distance between the geosynchronous satellite and the magnetopause surface current.

It is statistically confirmed that the SSC signal propagates with a speed of 400 $700 \mathrm{~km} / \mathrm{s}$ across the field lines in the magnetosphere. The result is consistent with that of W ILKEN et al. (1982).

\section{Acknowledgments}

The authors would like to express their appreciation to Prof. A. NisHIDA of the Institute of Space and Astronautical Science for his valuable comments and suggestions to the present study. The authors are very grateful to Dr. A. HARADA, director of the Kakioka Magnetic Observatory, for his understanding and encouragement to establish the present study. The GEOS data were provided by Dr. W. BaumJohanN of the Max Planck Institute. The SMS/GOES data were obtained from the World Data Center A, Solar-Terrestrial Physics.

\section{References}

Araki, T. (1977): Global structure of geomagnetic sudden commencement. Planet. Space Sci., 25, 373-384.

Araki, T. and Allen, J. H. (1982): Latitudinal reversal of polarization of the geomagnetic sudden commencement. J. Geophys. Res., 87, 5207-5216.

Baumjohann, W., Junginger, H., Haerendel, G. and Bauer, O. H. (1984): Resonant Alfvén waves excited by a sudden impulse. J. Geophys. Res., 89, 2765-2769.

Francis, W. E., Green, M. J. and Dessler, A. J. (1959): Hydromagnetic propagation of sudden commencement of magnetic storms. J. Geophys. Res., 64, 1643-1653.

Fritz, T. A. and Neeley, C. A. (1982): Geostationary satellites ATS 6 and SMS/GOES, description, position and data availability during IMS. The IMS Source Book, ed. by C. T. RuSSEL and D. J. Southwood. Washington, D.C., Am. Geophys. Union, 53-64.

Hughes, W. J. and Southwood, D. J. (1976): The screening effect of micropulsation signals by the atmosphere and ionosphere. J. Geophys. Res., 81, 3234-3240.

Kokubun, S. (1983): Characteristics of storm sudden commencement at geostationary orbit. J. Geophys. Res., 88, 10025-10033. 
KuWASHima, M. (1972): Long period geomagnetic pulsations associated with storm sudden commencement. Mem. Kakioka Mag. Obs., 15, 31-45.

Kuwashima, M., Tsunomura, S. and FukUnishi, H. (1984): SSC-associated magnetic variations at the geosynchronous altitude and on the ground. Mem. Natl Inst. Polar Res., Spec. Issue, 31, 12-26.

NishidA, A. (1964): Ionospheric screening effect and storm sudden commencement. J. Geophys. Res., 69, 1861-1874.

Nopper, R. W., Hughes, W. J., Maclennan, C. G. and McPherron, R. L. (1982): Impulse-excited pulsations during the July 29, 1977 event. J. Geophys. Res., 87, 5911-5916.

Olson, W. P. and Pfitzer, K. A. (1974): A quantitative model of the magnetospheric magnetic field. J. Geophys. Res., 79, 3739-3748.

ONDOH, T. (1970): Magnetospheric sudden commencement. J. Radio Res. Lab., 17, 199-212.

Patel, V. L. and Coleman, P. J., Jr. (1970): Sudden impulses in the magnetosphere observed at the synchronous orbit. J. Geophys. Res., 75, 7255-7260.

Saito, T. and Matsushita, S. (1967): Geomagnetic sudden commencement and sudden impulses. Planet. Space Sci., 15, 573-587.

Sakurai, T., Tonegawa, Y., Tomomura, K. and Kato, Y. (1984): A multi-satellite study of magnetic pulsations associated with a storm sudden commencement (SSC) as observed at synchronous orbit. Mem. Natl Inst. Polar Res., Spec. Issue, 31, 1-11.

TAMAO, T. (1964): A hydromagnetic interpretation of geomagnetic SSC. Rep. Ionos. Space Res. Jpn., 18, 16-31.

Wilken, B., Goertz, K., Baker, D. N., Higbie, P. R. and Fritz, T. A. (1982): The SSC on July 29, 1977 and its propagation within the magnetosphere. J. Geophys. Res., 87, 5901-5910.

(Received June 20, 1984; Revised manuscript received December 3, 1984) 